\title{
Effects of zirconia nanoparticles addition to experimental adhesives on radiopacity and microhardness
}

\author{
Gislaine Cristine Martins', Marcia Margarete Meier², Alessandro Dourado Loguercio ${ }^{3}$, \\ Fabielle Cecchin ${ }^{3}$, Osnara Maria Mongruel Gomes ${ }^{3}$, Alessandra Reis ${ }^{3}$ \\ 1'Department of Restorative Dentistry, Dental School, Pontifical Catholic University of Paraná, Curitiba, Paraná, PR, Brazil \\ ${ }^{2}$ Department of Chemist, State University of Santa Catarina, Joinville, SC, Brazil \\ ${ }^{3}$ Department of Restorative Dentistry, Dental School, State University of Ponta Grossa, Ponta Grossa, PR, Brazil
}

\begin{abstract}
Aim: To evaluate the radiopacity and microhardness (KHN) of experimental dental adhesives (EX). The experimental adhesive resins of the present study were formulated based on the simplified adhesive system Ambar (FGM). Methods: Five EX with different concentrations of zirconia nanoparticles [0(EX0), 15(EX15), 25(EX25), 30(EX30) e 50\%(EX50)] were incorporated in a UDMA/HEMA adhesive (control). Adper Single Bond ${ }^{\mathrm{TM}} 2$ (SB, 3M ESPE) was used as a commercial reference. For the radiopacity $(n=5), K H N(n=5)$, adhesive specimens were fabricated using a stainless steel mold. Data were submitted to one-way ANOVA and Tukey's test $(\alpha=0.05)$. Results: The filler addition on the EX showed radiopacity similar to enamel and higher than SB. The EX25, EX35 and EX50 showed higher KHN values when compared to the commercial SB. EX25, EX35 and EX50 showed higher KHN values when compared to the commercial SB. Conclusions: The results of the present investigation suggest that the addition of zirconia nanoparticles seems to be a good alternative to produce radiopaque adhesives with increased microhardness.
\end{abstract}

Keywords: radiology, contrast media, nanoparticles.

\section{Introduction}

Received for publication: September 09, 2013 Accepted: December 03, 2013

Correspondence to: Alessandra Reis Departamento de Odontologia, Universidade Estadual de Ponta Grossa Avenida Carlos Cavalcanti, 4748, CEP: 84030-900 Uvaranas, Ponta Grossa, PR, Brasil E-mail: reis_ale@hotmail.com
The radiopacity of adhesive materials is clinically relevant, mainly in technique-sensitive restorations, where evaluation of the tooth/restorative interface is critical ${ }^{1,2}$. Unfortunately, the great majority of the commercial adhesives available are radiolucent ${ }^{3}$ and they cannot be clearly detected in radiographs ${ }^{4}$ when applied in layers thicker than $40 \mu \mathrm{m}$. This is a pertinent clinical concern since adhesive layers should be distinguished from marginal gaps with potential for secondary caries.

The radiopacity of esthetic restorative materials has been established as an important requirement, improving the radiographic diagnosis. To the extent of our knowledge, the flowable composites ${ }^{5,6}$, composite resins ${ }^{7}$ or resin cements $\mathrm{s}^{6,8}$ available are radiopaque and only bonding agents are still radiolucent ${ }^{9}$. The development of radiopaque adhesive systems can avoid inappropriate replacements ${ }^{10,11}$ due to misinterpretations in the diagnosis of secondary caries $^{2,10,12}$ and detection of gaps near the restoration ${ }^{4,12}$. Thus, the studies should focus on 
the investigation of bonding features and mechanical properties of radiopaque adhesive systems.

Recently, there has been a great interest in the application of nanotechnology in resin-based materials ${ }^{13,14}$ to produce dental composite materials with increased hardness ${ }^{7,13,15}$. These promising findings led investigators to evaluate the effects of filler addition on the mechanical properties $^{16-20}$ as well as bonding features of adhesives ${ }^{18,22}$. However few of them incorporated nano-sized filler particles into the adhesive formulations ${ }^{13,15}$ and evaluated the role of nanofillers on the material's radiopacity ${ }^{18,20}$. Therefore, the aim of the present investigation was to evaluate the incorporation of varied concentrations of zirconia nanofiller into a two-step etch-and-rinse adhesive on the material's radiopacity and microhardness.

\section{Material and methods}

This research project was approved by the Institutional Review Board from the local Dental School under protocol \# 28/2010.

The experimental adhesive resins from the present study were formulated using the simplified adhesive system Ambar (FGM Dental Products, Joinville, SC, Brazil) as base. This material was specifically formulated for this study without any filler content. The detailed composition of this adhesive system, as provided by the manufacturer, can be seen in Table 1. The simplified etch-and-rinse commercial adhesive system (Adper Single Bond ${ }^{\mathrm{TM}} 2$; $3 \mathrm{M}$ ESPE, St. Paul, MN, USA) was used as reference (Table 1).

Zirconia oxide nanoparticles (20-30 $\mathrm{nm}$ average particle size) (Transparent Materials, Rochester, Nova York, USA) were silanized by gamma-methacryloxypropyltrimethoxysilane (Aldrich Chemical Co., Milwaukee, WI,
USA) as reported before ${ }^{23}$. After the silanization process, the nanoparticles were dried for $24 \mathrm{~h}$ at $37^{\circ} \mathrm{C}$ and then disaggregated in a pistil. Five experimental adhesive systems were formulated according to the filler weight percentage (wt\%): 0 (EX0), 15 (EX15), 25 (EX25), 35 (EX35) and 50\% (EX50).

Using a circular stainless steel mold, five specimens measuring $5.0 \mathrm{~mm}$ in diameter and $1.0 \mathrm{~mm}$ thick were prepared for each material. The adhesive was dispensed in the mold until complete filling. All visible air bubbles trapped in the adhesive solution were carefully removed. The solvent was evaporated by gentle air blowing from a dental syringe for $40 \mathrm{~s}$. Each specimen was polymerized for $80 \mathrm{~s}$ with a visiblelight curing unit (VIP; Bisco Inc., Schaumburg, IL, USA) with a power density $450 \mathrm{~mW} / \mathrm{cm}^{2}$. Enamel and dentin specimens were obtained from $1.0-\mathrm{mm}$ thick longitudinal sections of human third molars previously stored in $0.5 \%$ thymol and used within 6 months after extraction. Slices were prepared using a low-speed diamond blade (Isomet 1000; Buehler, Lake Bluff, IL, USA) mounted in a cutting machine under water cooling.

A total of five radiographs were made. Each radiograph was taken with one specimen of each experimental condition and the enamel-dentin slice positioned on the digital sensor. An digital radiography was then taken with an exposure time of $0.2 \mathrm{~s}$. The radiographic position was standardized: the radiographic central beam focusing in a $90^{\circ}$ angle with the surface of the image receptor, at a $30 \mathrm{~cm}$ focus-object distance and parallelism between the sensor and the specimens with the Heliodent Vario machine (Sirona, Bensheim, Germany). The digital radiopacity (\% white) was measured by pixels counting using the UTHSCSA ImageTool 3.0 software (Department of Dental Diagnostic Science, University of Texas Health Science Center, San Antonio, TX, USA).

Data for each property was subjected to one-way ANOVA.

Table 1. Composition of adhesive systems and application mode.

\begin{tabular}{|c|c|c|c|}
\hline Adhesive systems & Composition & Application mode & Batch number \\
\hline $\begin{array}{l}\text { Adper Single Bond }{ }^{\mathrm{TM}} \\
\text { 2(3M ESPE, St. Paul, } \\
\text { MN, USA) }\end{array}$ & $\begin{array}{l}\text { Bis-GMA; polyalkenoic acid co- } \\
\text { polymer; dimethacrylates; HEMA; } \\
\text { photoinitiators; ethanol; water; } \\
\text { nanofiller particles }\end{array}$ & $\begin{array}{l}\text { 1. Apply generous amounts of } \\
\text { adhesive. Actively scrub for } \\
\text { 15s; } \\
\text { 2. Application of a second coat } \\
\text { of adhesive, as above; }\end{array}$ & $\begin{array}{c}8 R F \\
2011-05\end{array}$ \\
\hline $\begin{array}{l}\text { Experimental } \\
\text { adhesives* (FGM } \\
\text { Dental Products, } \\
\text { Joinville, SC, Brazil) }\end{array}$ & $\begin{array}{l}\text { UDMA }(5-40) \text {, HEMA }(5-40) \text {, } \\
\text { methacrylate acidic monomers }(1- \\
20) \text { methacrylate hydrophilic } \\
\text { monomers }(5-40) \text {, silanized silicon } \\
\text { dioxide }(<1) \text {, camphorquinone }(<1) \text {, } \\
\text { 4-EDAMB }(<1) \text {, ethanol }(<20)\end{array}$ & $\begin{array}{l}\text { 3. Removal of excess solvent } \\
\text { by gently drying with an air- } \\
\text { stream for } 15 \mathrm{~s} \text { at } 15 \mathrm{~cm} \text { away } \\
\text { from the surface, gradually } \\
\text { bringing it to within } 10 \mathrm{~mm} \text { of } \\
\text { distance; } \\
\text { 4. Light cure for } 10 \mathrm{~s}\end{array}$ & $\begin{array}{c}\text { Ex0: } \\
0606231 \\
\text { Ex15: } \\
080410 \\
\text { Ex25: } \\
080410 \\
\text { Ex35: } \\
080410 \\
\text { Ex50: } \\
080410\end{array}$ \\
\hline
\end{tabular}


Post-hoc multiple comparisons were performed using Tukey's test at a significance level of $5 \%$.

\section{Results}

One-way ANOVA detected statistically significant difference among groups (Table $2, \mathrm{p}<0.001$ ). All experimental bonding adhesives showed radiopacity similar to enamel, except for EX0 and SB. These two adhesives showed radiopacity similar to the dentin substrate. For KHN oneway ANOVA detected significant differences between groups (Table 2, p < 0.0001). In regard to KHN, the addition of filler loading equal or higher than $25 \%$ produced materials with increased microhardness when compared with the commercial SB. The unfilled EX0 and the lightly filled EX15 showed intermediate microhardness between these extremes.

Table 2. Means and standard deviations the enamel, dentin and adhesive systems radiopacity by pixel intensity as well as KNOOP microhardness of the adhesive solutions.

\begin{tabular}{llc}
\hline Groups & Pixel intensity & Microhardness (KHN) \\
Enamel & $68.8 \pm 15.3 \mathrm{~A}$ & - \\
Dentin & $33.0 \pm 8.1 \mathrm{~B}$ & - \\
SB & $26.9 \pm 1.2 \mathrm{~B}$ & $3.3 \pm 1.2 \mathrm{C}$ \\
EX0 & $27.1 \pm 1.0 \mathrm{~B}$ & $5.8 \pm 0.7 \mathrm{BC}$ \\
EX15 & $60.5 \pm 7.9 \mathrm{~A}$ & $5.7 \pm 0.3 \mathrm{BC}$ \\
EX25 & $71.2 \pm 6.7 \mathrm{~A}$ & $7.5 \pm 1.5 \mathrm{AB}$ \\
EX35 & $61.0 .9 \pm 9.2 \mathrm{~A}$ & $8.8 \pm 1.8 \mathrm{~A}$ \\
EX50 & $73.3 .0 \pm 7.4 \mathrm{~A}$ & $8.8 \pm 1.8 \mathrm{~A}$ \\
\hline
\end{tabular}

Comparisons are valid within columns. Averages identified with the same letters indicate statistically similar means $(p>0.05)$.

\section{Discussion}

It is noteworthy to mention that the monomeric composition of the commercially available two-step etchand-rinse adhesive Ambar (FGM Dental Products, Brazil) was employed. This simplified adhesive contains nanofillers, which were especially removed by the manufacturer preparing the evaluated experimental adhesives. Therefore, the experimental adhesives contained only the filler loading added by the authors.

The radiopacity of esthetic restorative materials has been established as an important requirement, improving radiographic diagnosis ${ }^{1,2,24}$. Radiolucent areas around restorations may result from either a halo effect or the radiographic density of the adhesives. Therefore, the use of an adhesive with radiopaque fillers can avoid inappropriate replacements ${ }^{10,11}$ due to misinterpretations in the diagnosis of secondary $\operatorname{caries}^{2,10,12}$. For adequate assessment of the restoration quality both at baseline and in recall examinations, radiographic evaluations are very useful and for such, dental materials should be sufficiently radiopaque to be detected against a background of sound and caries-affected enamel and dentin substrate, and thus allow correct evaluation of the presence of secondary caries, marginal defects, contour of restoration, and contact with adjacent teeth, cement overhangs and interfacial gaps ${ }^{1,2,9}$.

To the extent of the authors' knowledge only one study investigated the impact of filler addition on the adhesive radiopacity $^{22}$ and this is therefore a novel study that attempts to investigate this issue. The results of the present study showed that the addition of zirconia nanoparticles yielded enamel radiopacity to the experimental adhesives evaluated. Even the smallest percentage of zirconia nanoparticles evaluated in this study (15\%) produced a radiopaque experimental adhesive similar to the radiopacity of the enamel substrate. Similarly Schulz et al. also observed increased adhesive radiopacity after inclusion of agglomerated $\mathrm{Ta}_{2} \mathrm{O}_{5} / \mathrm{SiO}_{2}$ nanoparticles.

Dental adhesives are intricate mixtures of components and they are designed to bond composite resins to enamel and dentin ${ }^{25,26}$. Irrespective of the number of bottles, an adhesive system typically contains resin monomers, curing initiators, inhibitors, stabilizers, solvents and inorganic filler. Each one of these components has a specific function ${ }^{25}$. Although the addition of filler to adhesives has shown to be beneficial $^{20}$ this finding is not consensual in the literature ${ }^{20,27}$.

The addition of filler particles to composite resins is made in an attempt to improve the mechanical properties of dental composites $^{13,25,28,29}$. Similarly, the present investigation showed that the addition of filler loading higher equal to or higher than $25 \%$ allowed the increase in the microhardness of the experimental adhesives. A recent study also demonstrated that the addition of hydroxyapatite nanoparticles ${ }^{30}$ and niobium pentoxide $^{31}$ also produced an adhesive layer with increased microhardness and other superior properties.

The commercial SB adhesive showed the lowest KHN. This means that the attainment of higher microhardness is not dependent only on the filler loading. An adhesive system with adequate and balanced monomer composition blend may also lead to the production of a polymeric material with increased properties. Compared to the commercial SB adhesive, the unfilled experimental adhesive (EX0) showed higher $\mathrm{KNH}$ and such difference may be attributed to composition differences in monomer blends.

The addition of filler loading in moderate concentrations (EX25 and EX35) produced radiopaque materials. Compared to the commercial SB adhesive, the unfilled experimental adhesive (EX0) with higher KNH that were either improved or remained unchanged compared to the unfilled version. The results of the present investigation suggest that the addition of zirconia nanoparticles seems to be a good alternative to produce radiopaque adhesives with increased microhardness. Further studies should focus on the enamel and dentin bonding strength of adhesive systems with zirconia nanoparticles.

\section{Acknowledgments}

The authors would like to thanks FGM Dental Products for the generous donation and manipulation of the products employed in this study. This study was partially supported 
by the National Council for Scientific and Technological Development (CNPq) under grants 301937/2009-5 and $301891 / 2010-9$. The authors of this study are very grateful to Iverson E. Woyceichoski for the help in the radiographs and Luiz Lima Junior for the help in microhardness test.

\section{References}

1. TveitAB, Espelid I. Radiographic diagnosis of caries and marginal defects in connection with radiopaque composite fillings. Dent Mater. 1986; 2: 159-162.

2. Espelid I, TveitAB, Erickson RL, Keck SC, Glasspoole EA. Radiopacity of restorations and detection of secondary caries. Dent Mater. 1991; 7: 114-117.

3. Hotta M, Yamamoto K. Comparative radiopacity of bonding agents. $\mathrm{J}$ Adhes Dent. 2009; 11: 207-212.

4. Opdam NJ, Roeters FJ, Verdonschot EH. Adaptation and radiographic evaluation of four adhesive systems. J Dent. 1997; 25: 391-397.

5. Imperiano MT, Khoury HJ, Pontual MLA, Montes MAJR, Silveira MMF. Comparative radiopacity of four low-viscosity composites Braz J Oral Sci. 2007; 6: 1278-1282.

6. Ergücü Z, Türkün LS, Onem E, Guneri P. Comparative radiopaticity of six flowable resin composites. Oper Dent. 2010; 35: 436-440.

7. Groninger AIS, Soares GP, Sasaki RT, Ambrosano GMB, Lovadino JR, Aguiar FHB. Microhardness of nanofilled composite resin light-cured by LED or QTH units with different times. Braz J Oral Sci. 2011; 10: 189-192.

8. Tanomaru-Filho M, da Silva GF, Duarte MA, Goncalves M, Tanomaru JM. Radiopacity evaluation of root-end filling materials by digitization of images. J Appl Oral Sci. 2008; 16:376-379.

9. Bouschlicher MR, Cobb DS, Boyer DB. Radiopacity of compomers, flowable and conventional resin composites for posterior restorations. Oper Dent. 1999; 24: 20-25.

10. Alonso RC, Sinhoreti MA, Correr Sobrinho L, Consani S, Goes MF. Effect of resin liners on the microleakage of class $\mathrm{V}$ dental composite restorations. J Appl Oral Sci. 2004; 12: 56-61.

11. Pamir T, Kaya AD, Baksi BG, Sen BH, Boyacioglu $H$. The influence of bonding agents on the decision to replace composite restorations. Oper Dent. 2010; 35: 572-578.

12. Akerboom HB, Kreulen CM, van Amerongen WE, Mol A. Radiopacity of posterior composite resins, composite resin luting cements, and glass ionomer lining cements. J Prosthet Dent. 1993; 70: 351-355.

13. Hosseinalipour M, Javadpour J, Rezaie H, Dadras T, Hayati AN. Investigation of mechanical properties of experimental Bis-GMA/TEGDMA dental composite resins containing various mass fractions of silica nanoparticles. J Prosthodont. 2010; 19: 112-117.

14. Karabela MM, Sideridou ID. Synthesis and study of properties of dental resin composites with different nanosilica particles size. Dent Mater. 2011; 27: 825-835.

15. Klapdohr S, Moszner N. New inorganic components for dental filling composites. Chemical Monthly. 2005;136(1):21-45.

16. Giannini M, Liberti MS, Arrais CA, Reis AF, Mettenburg D, Rueggeberg FA. Influence of filler addition, storage medium and evaluation time on biaxial flexure strength and modulus of adhesive systems. Acta Odontol Scand. 2012; 70: 478-484.

17. Giannini M, Mettenburg D, Arrais CA. Rueggeberg FA. The effect of filler addition on biaxial flexure strength and modulus of commercial dentin bonding systems. Quintessence Int. 2011; 42: e39-43.

18. Kim JS, Cho BH, Lee IB, Um CM, Lim BS, Oh MH, et al. Effect of the hydrophilic nanofiller loading on the mechanical properties and the microtensile bond strength of an ethanol-based one-bottle dentin adhesive. J Biomed Mater Res B Appl Biomater. 2005; 72: 284-291.

19. Pongprueksa P, Kuphasuk W, Senawongse P. The elastic moduli across various types of resin/dentin interfaces. Dent Mater. 2008; 24 : 1102-1106.
20. Can Say E, Nakajima M, Senawongse P, Soyman M, Ozer F, Ogata M, et al. Microtensile bond strength of a filled vs unfilled adhesive to dentin using self-etch and total-etch technique. J Dent. 2006; 34: 283-291.

21. Lee YK, Pinzon LM, O'Keefe KL, Powers JM. Effect of filler addition on the bonding parameters of dentin bonding adhesives bonded to human dentin. Am J Dent. 2006; 19: 23-27.

22. Schulz H, Schimmoeller B, Pratsinis SE, Salz U, Bock T. Radiopaque dental adhesives: dispersion of flame-made Ta2O5/SiO2 nanoparticles in methacrylic matrices. J Dent. 2008; 36: 579-587.

23. Martins GC, Meier MM, Loguercio AD, Reis A, Gomes JC, Gomes OM. Effects of adding barium-borosilicate glass to a simplified etch-and-rinse adhesive o radiopacity and selected properties. J Adhes Dent. 2013 Oct 2. [Epub ahead of print].

24. Matteson SR, Phillips C, Kantor ML, Leinedecker T. The effect of lesion size, restorative material, and film speed on the detection of recurrent caries. Oral Surg Oral Med Oral Pathol. 1989; 68: 232-237.

25. Van Landuyt KL, Snauwaert J, De Munck J, Peumans M, Yoshida Y, Poitevin A, et al. Systematic review of the chemical composition of contemporary dental adhesives. Biomaterials. 2007; 28: 3757-3785.

26. Finger WJ,Fritz UB. Resin bonding to enamel and dentin with one-component UDMA/HEMA adhesives. Eur J Oral Sci. 1997; 105: 183-186.

27. Lee JH, Um CM, Lee IB. Rheological properties of resin composites according to variations in monomer and filler composition. Dent Mater. 2006; 22: 515-526.

28. Conde MC, Zanchi CH, Rodrigues-Junior SA, Carreno NL, Ogliari FA, Piva E. Nanofiller loading level: Influence on selected properties of an adhesive resin. J Dent. 2009; 37: 331-335.

29. Kim KH, Ong JL, Okuno O. The effect of filler loading and morphology on the mechanical properties of contemporary composites. J Prosthet Dent. 2002; 87: 642-649.

30. Leitune VC, Collares FM, Trommer RM, Andrioli DG, Bergmann CP, Samuel SM. The addition of nanostructured hydroxyapatite to an experimental adhesive resin. J Dent. 2013; 41: 321-327.

31. Leitune VC, Collares FM, Takimi A, de Lima GB, Petzhold CL, Bergmann $\mathrm{CP}$, et al. Niobium pentoxide as a novel filler for dental adhesive resin. $J$ Dent. 2013; 41: 106-113. 